\title{
Mechanism of biological control of Rhizoctonia damping-off of cucumber by a non-pathogenic isolate of binucleate Rhizoctonia
}

\author{
Mohsen Mohamed Elsharkawy ${ }^{1}$, Naglaa Hassan ${ }^{2,3}$, Remedios Villajuan-Abgona ${ }^{2}$ and \\ Mitsuro Hyakumachi ${ }^{4 *}$
}

${ }^{1}$ Department of Agricultural Botany, Faculty of Agriculture, Kafr El-Sheikh University, Kafr El-Sheikh 33516, Egypt.

${ }^{2}$ United Graduate School of Agricultural Science, Gifu University, 1-1 Yanagido, Gifu 501-1193, Gifu, Japan.

${ }^{3}$ Department of Plant Pathology, Faculty of Agriculture, South Valley University, Qena 83523, Egypt.

${ }^{4}$ Laboratory of Plant Pathology, Faculty of Applied Biological Sciences, Gifu University, 1-1 Yanagido,

Gifu City 501-1193, Japan.

Accepted 24 January, 2014

\begin{abstract}
The interaction of binucleate Rhizoctonia (BNR) anastomosis group (AG)-A isolate W7, Rhizoctonia solani AG-4 and cucumber seedlings were investigated to elucidate the mechanism of biocontrol of Rhizoctonia solani by BNR. Hypocotyls of Cucumis sativus L. cv. Jibai were inoculated with a virulent isolate of $R$. solani AG-4 isolate C4 and examined with light microscopy and scanning and transmission electron microscopy. The hyphae of the virulent isolate colonized the outer surface of the hypocotyl and penetrated the epidermal and cortical cells to the pith of hypocotyls. The hyphae of a non-pathogenic species of BNR isolate W7 did not penetrate the cortical cells but instead colonized the outer epidermal cells $12 \mathrm{~h}$ after inoculation. Accumulation of mucilage occurred on the surface after dense colonization of the hypocotyls surface by the BNR. Observation of the hypocotyls surface pre-inoculated with BNR and challenged inoculated with $R$. solani showed constricted and deformed hyphae of $R$. solani, which were prevented to penetrate the epidermal cells. Pre-inoculating of BNR isolate caused profused formation of the mucilage which lysed BNR hyphae and restricted the growth of $R$. solani. The mucilage was identified as pectic substances. Analysis of pectin contents from dried hypocotyls tissues showed highly methylated pectin with low uronic acid contents in the seedlings inoculated with $R$. solani and unprotected by BNR while BNR- treated seedlings showed less methylated pectin and high amount of uronic acid. Furthermore, the BNR-inoculated seedlings showed significant $(P=0.05)$ increase in calcium, indicating high amount of wall-bound cations in cell walls. Pectic substances accumulation and increased calcium in the cucumber tissues greatly contributed in the protection of cucumber seedlings against Rhizoctonia damping off by a non-pathogenic species of Rhizoctonia.
\end{abstract}

Key words: Rhizoctonia solani, binucleate Rhizoctonia, cucumber, biological control.

\section{INTRODUCTION}

The use of hypovirulent and non-pathogenic isolates of Rhizoctonia spp. has been potentially shown as effective biocontrol agents. Among Rhizoctonia spp., binucleate Rhizoctonia was effective in controlling diseases caused by Rhizoctonia spp. and Pythium spp. Although many studies have reported the role of binucleate Rhizoctonia in biological control of Rhizoctonia spp. and Pythium spp. in different plant species such as sugarbeet (Herr, 1988), 
corn (Pascual et al., 2000), cotton (Jabaji-Hare and Neate, 2005), radish (Sneh et al., 2004), potato (Escande and Echandi, 1991), bean (Cardoso and Echandi, 1987a, 1987b), bedding plants (capsicum and celosia) and cucumber (Cubeta and Echandi, 1991; Villajuan-Abgona et al., 1996a), little is known about the mechanism of biological control.

The possible mechanisms of protection of creeping bentgrass, bean and cotton seedlings by a binucleate Rhizoctonia (BNR) and hypovirulent Rhizoctonia solani isolate have been studied but the results have led to different assumptions and conclusions. For instance, competition for nutrients and host induced resistance appeared to be the plausible mechanisms for protection of bean and creeping bentgrass (Burpee and Goulty, 1984; Cardoso and Echandi, 1987b). While in case of cotton seedlings, competition for infection sites or dense outer surface colonization was pointed out by Sneh et al. (1989).

Host-pathogen relationship between the virulent Rhizoctonia spp. and different hosts have been described in previous studies (Christou, 1962; Armentrout and Downer, 1987), but details on the histological study of host-fungus relationship which are essential for understanding the mode of action by hypovirulent or nonpathogenic isolates have not been thoroughly elucidated.

The present study was undertaken to describe in details, through histological study, the mode of colonization by the non-pathogenic BNR and the penetration of the hypocotyls surface and taproot of cucumber seedlings by a virulent $R$. solani isolate. To justify this initial finding, the result was compared with biochemical studies which revealed the importance of pectic substance and its influence in the suppression of the disease. Furthermore, the reasons of the protection provided by the nonpathogenic BNR to cucumber seedlings against Rhizoctonia damping-off were clarified.

\section{MATERIALS AND METHODS}

\section{Fungal isolate}

BNR isolate W7 (AG-A) obtained from tomato, non-pathogenic to several hosts and effectively control damping-off disease in cucumber (Villajuan-Abgona et al., 1996a) was used as the biocontrol agent. A virulent $R$. solani isolate C4 (AG-4), isolated from soil, causing severe damping-off disease to radish and cucumber was used as the challenge isolate.

\section{Inoculation procedure}

Cucumber (Cucumis sativus L. Cv. Jibai) seeds were surfacedisinfested in $70 \%$ ethyl alcohol (EtOH) for 1 min followed by $2 \%$ sodium hypochlorite with three drops of Tween 20 (polyoxyethylene sorbitan monolaurate) (Nacalai Tesque, Inc., Kyoto, Japan) for 30 min. The seeds were rinsed three times with sterile distilled water (SDW) and pre-germinated in between two layers of $90 \mathrm{~mm}$ diameter filter paper (Whatman No. 1, camlab, UK). Five seedlings were transferred to $2 \%$ water agar (WA) in Petri dish and allowed to grow for two days in growth chamber $(16 \mathrm{~h}$ photoperiod with a daytime illuminance of $250 \mu \mathrm{E} \mathrm{m} \mathrm{m}^{-2 \mathrm{~s}-1}$ ) at $25^{\circ} \mathrm{C}$. Mycelial disks (3-mm diameter) of the non-pathogenic BNR (from the advancing margin of three-day-old pure culture on potato dextrose agar (PDA)) were inoculated on the base of five hypocotyls of two day-old seedlings and incubated for $12 \mathrm{~h}$ and another set of treatment for $24 \mathrm{~h}$. 1) After incubation of the non-pathogenic BNR for 12 and $24 \mathrm{~h}, 3 \mathrm{~mm}$ diameter mycelia disks of the virulent $R$. solani (grown on PDA) were inoculated on the same hypocotyls next to the previously inoculated mycelial disks of the non-pathogenic BNR and incubated for 12 and $24 \mathrm{~h}$ in the same growth chamber. Other treatments consist of 2) seedlings inoculated with non-pathogenic BNR alone, 3 ) seedlings inoculated with the virulent $R$. solani without the nonpathogenic BNR, 4) seedlings inoculated with $3 \mathrm{~mm}$ diameter disks of PDA only, 5) seedlings inoculated with $3 \mathrm{~mm}$ diameter mycelia disks of killed pathogen (autoclaved at $120^{\circ} \mathrm{C}$ for $30 \mathrm{~min}$ ) and 6) uninoculated seedlings.

All treatments were incubated for $12-24 \mathrm{~h}$ and each treatment was replicated three times. After incubation, the seedling hypocotyls and root portions were cut into segments for scanning electron microscopy (SEM) and paraffin sectioning for light microscopy. This study was repeated twice and observations were made on three replicates (with 10 segments per replicate) for each treatment of SEM and 100 paraffin sections were observed for each replicate in light microscopy.

\section{Scanning electron microscopy}

After incubation of the inoculated seedlings, the whole hypocotyl (including the areas inoculated with mycelia disks) and root portions of seedlings of all treatments were cut into segments $(6 \mathrm{~mm})$ and fixed for $2 \mathrm{~h}$ in $2 \%$ glutaraldehyde with $0.05 \mathrm{M}$ sodium cacodylate buffer (pH 7.4). The tissues were post-fixed in $1 \% \mathrm{OsO}_{4}$ with $0.05 \mathrm{M}$ phosphate buffer $(\mathrm{pH} 7.4)$ for $2 \mathrm{~h}$ and dehydrated through a graded ethyl alcohol $(\mathrm{EtOH})$ series. The fixed specimens were then transferred to increasing concentrations of isoamyl acetate-EtOH mixture up to $100 \%$ isoamyl acetate concentration and critical dried point (JCPD-5, Japan Electron Optics Laboratory (Jeol), Ltd, Japan). Tissues were coated with gold on a JFC-1100 sputter coater (Jeol. Ltd, Japan) and examined with a field emission scanning microscope (JSM-820, Jeol, Ltd., Japan) at $10 \mathrm{kV}$ and photographed. Replicate of the same samples were observed with a wavelength-dispersive X-ray microanalyzer (JSM-35CF/FCS, Jeol, Ltd, Japan) to study the distribution of elements on the hypocotyls surface of inoculated and un-inoculated cucumber seedlings.

\section{Light microscopy}

Hypocotyls and root segments $(6 \mathrm{~mm})$ were fixed for $24 \mathrm{~h}$ in FAA (37\% formaldehyde-acetic acid- $50 \% \mathrm{EtOH})(6.5: 2.5: 91)$ (Johansen, 1940), washed with $\mathrm{EtOH}$ and dehydrated through increasing concentrations up to $100 \%$ butyl alcohol and embedded in paraffin (Wako, Osaka, Japan, $\left.52-54^{\circ} \mathrm{C} \mathrm{mp}\right)$. Transverse sections $(16 \mu \mathrm{m}$ 
thick) of the cucumber hypocotyls and roots were cut using microtome (ERMA optical Works, Japan), mounted on glass slides with Haupt's adhesive (Johansen, 1940) and stained with phenylthionin $(0.1 \%$ in $5 \%$ phenol solution) (Lauth's violet) (Nacalai Tesque, Inc., Kyoto, Japan) followed by staining in saturated solution of Orange G (Kishida chemicals Co., Ltd., Japan) in 100\% $\mathrm{EtOH}$ (Stoughton, 1930). Thionin and Orange $\mathrm{G}$ were used to differentiate pectic substances and cellulose in cross-sections, respectively. Permanent mounts of the paraffin sections were examined with light microscopy (Olympus BH, Tokyo, Japan) and photographed in 135 ASA 100 film (Fujifilm, Tokyo, Japan) using camera AFM 35S (Nikon, Tokyo, Japan). Free-hand sections were taken from fresh samples, stained with aqueous ruthenium red $(0.02 \%)$ (ammoniated ruthenium oxychloride) (Sigma Chemicals Co., St. Louis, MO) and used to identify pectin (Johansen, 1940; Sterling, 1970).

\section{Inoculation procedure and assessment of disease severity}

The same isolates were used and the above inoculation method was followed in this experiment consisting of four treatments: (1) seedlings inoculated with non-pathogenic BNR and incubated for two days and then challenge inoculated with virulent $R$. solani and again incubated for 6 days; 2) seedlings inoculated with the nonpathogenic BNR and incubated for 6 days; 3 ) seedlings inoculated with virulent $R$. solani without non-pathogenic BNR and incubated for three days; 4) and un-inoculated seedlings also incubated for six days). All treatments were kept in growth chamber (16 h photoperiod with a daytime illuminance of $250 \mu^{-2} \mathrm{sm}^{-1}$ ) after each inoculation. The treatments were prepared in five replicates and disease severity and sample preparations were done after six days. However, for seedlings inoculated with virulent $R$. solani without non-pathogenic BNR, disease severity and sample preparation were done three days after incubation because prolonged incubation can result in macerated or disintegrated hypocotyl tissues and make sample preparation difficult. Disease severity rating was determined using the following rating scheme (VillajuanAbgona et al., 1996a), where 0 = healthy, no lesions on the hypocotyl; $1=$ one or two light brown lesions of $<0.25 \mathrm{~mm} ; 2=$ light brown lesions of $<0.5 \mathrm{~mm}$ and water soaked areas covering $<10 \%$ of the hypocotyls; 3 = light to dark brown lesions $>1.0 \mathrm{~mm}$ which coalesced with other lesions and water soaked areas covering $>10 \%$ to $<100 \%$ of the hypocotyl (leaves not yet wilted and hypocotyls still firm and upright); 4 = collapsed hypocotyls with wilted leaves of dead seedlings. Inoculation procedures for disease severity ratings and samples preparation for tissue analysis were done twice.

\section{Analysis for pectic substances in hypocotyls tissues}

The pectin contents of hypocotyls tissues were estimated following the procedure of Boos (1948). One hundred mg of dried and ground (40-mesh) samples of hypocotyls tissues were placed in $50 \mathrm{ml}$ distillation flasks. $4 \mathrm{ml}$ of $1 \mathrm{~N} \mathrm{NaOH}$ were added to each flask and the mixture was allowed to stand for 30 min to saponify the pectin. This was followed by addition of $4.25 \mathrm{ml}$ of $1 \mathrm{~N} \mathrm{HCl}$ and distillation of the liberated methanol. The distillate was collected in $10 \mathrm{ml}$ volumetric flask and diluted to $10 \mathrm{ml}$ with water. Aliquot of $1 \mathrm{ml}$ of the samples was transferred to a separate $10 \mathrm{ml}$ volumetric flask and $3 \mu \mathrm{m}$ diluted $\mathrm{H}_{3} \mathrm{PO}_{4}$ and $5 \mu \mathrm{l} 5 \% \mathrm{KMnO}_{4}$ were added. The samples were held at room temperature for $10 \mathrm{~min}$ and occasionally swirled to ensure oxidation of $\mathrm{CH}_{3} \mathrm{OH}$ to $\mathrm{CH}_{2} \mathrm{O}$. Then, $10 \mu \mathrm{l}$ $\mathrm{NaHSO}_{3}$ was added to reduce the excess permanganate. $4 \mathrm{ml}$ concentrated $\mathrm{H}_{2} \mathrm{SO}_{4}$ was added slowly to each sample. The samples were placed in water bath at $60^{\circ} \mathrm{C}$ and held with occasional swirling for $15 \mathrm{~min}$. The flasks were cooled in ice bath and water was added to make a $10 \mathrm{ml}$-volume. After the samples reached room temperature, the absorbance of the samples was determined spectrophotometrically (Hitachi U2000A, Hitachi Ltd., Tokyo, Japan) at $580 \mathrm{~nm}$. The quantity of methanol was calculated from a standard curve and expressed in meq per gram dry weight of tissue and percentage of methanol was calculated.

Uronic acid contents of the hypocotyls tissues were determined following the procedures of McCready and McComb (1952). Dry tissues were ground to pass a 40 -mesh screen and desugared by extraction with $70 \% \mathrm{EtOH}$. The extraction consisted of permitting the dry tissue to stand in $70 \% \mathrm{EtOH}(100 \mathrm{ml} / \mathrm{g}$ tissue) for $18 \mathrm{~h}$ at room temperature followed by filtration on Whatman No. 1 filter paper and washing with one-fourth of the original volume of $70 \%$ $\mathrm{EtOH}$. Desugared tissues were dried at $80^{\circ} \mathrm{C}$ and moistened with $95 \% \mathrm{EtOH}$. Two hundred $\mathrm{ml}$ of $0.5 \%$ Versene solution described by McCready and McComb (1952) were added to each sample to sequester multivalent cations. After adjusting the sample to $\mathrm{pH}$ 11.5 , it was held at room temperature for $30 \mathrm{~min}$ to permit saponification of pectin. The $\mathrm{pH}$ was then adjusted to $\mathrm{pH} 5.0-5.5$, and $0.1 \mathrm{~g}$ of pectinase (EC 3.2.1.15, from Aspergillus niger) (Sigma Chemical Co., St. Louis, MO) was added to each sample to solubilize the pectic substances. The samples were stirred for $1 \mathrm{~h}$ then diluted with water to $250 \mathrm{ml}$. The mixture was filtered through No. 1 Whatman filter paper (90 mm-diameter) discarding the first few millilitres. From the filtrate, $2 \mathrm{ml}$ aliquot was diluted to $10 \mathrm{ml}$ in a separate flask, mixed thoroughly and set aside to be used for analysis. In a separate tube, $12 \mathrm{ml}$ of concentrated $\mathrm{H}_{2} \mathrm{SO}_{4}$ was cooled to $3^{\circ} \mathrm{C}$ and $2 \mathrm{ml}$ from the mixture $(2 \mathrm{ml}$ aliquot $+10 \mathrm{ml}$ water) was added and mixed thoroughly. The mixture was cooled to $3^{\circ} \mathrm{C}$ and then heated in boiling water for $10 \mathrm{~min}$. After cooling the mixture to about $20^{\circ} \mathrm{C}, 1 \mathrm{ml}$ of $0.15 \%$ carbazole reagent (Sigma Chemical Co., St. Louis, MO) was added to each tube, the contents were mixed thoroughly and allowed to stand at room temperature for $25 \pm 5 \mathrm{~min}$. The absorbance of the samples was determined at $520 \mathrm{~nm}$ using Hitachi U2000A spectrophotometer (Hitachi Ltd., Tokyo, Japan). A standard curve was used to calculate the amount of anhydrouonic acid using galacturonic acid monohydrate as the standard. Results expressed as meq anhydrogalacturonic acid present per gram dry weight of tissue before desugaring.

\section{Analysis for total elements in hypocotyls tissues}

Inductively coupled plasma atomic emission spectrometry was used to determine the total elements present in hypocotyls of cucumber. Cucumber hypocotyls were separated from leaf and root portion of the seedlings, oven dried at $80^{\circ} \mathrm{C}$ and weighed. The oven dried tissues were ground to pass a 40 -mesh screen and $0.5 \mathrm{~g}$ samples per treatment were digested to dryness in $10 \mathrm{ml} \mathrm{HNO}_{3}$. The residue was redissolved in $10 \mathrm{ml} 35 \% \mathrm{HCl}$ and $1 \mathrm{ml}$ Itolium standard solution (Kishida Chemicals Co., Ltd., Osaka, Japan) and diluted with 100 $\mathrm{ml}$ of cold purified distilled water. Analyses were done using inductively coupled plasma atomic emission spectrometer (Model JY48P) (Carrier gas- Argon) (Seiko Co., Osaka, Japan). The total concentrations of elements in samples were expressed in milliequivalent per gram dry weight.

\section{Data analysis}

Experiments for biological study was laid out in $2 \times 4$ factorial in randomized complete block design with varied time of incubation period (12 and $24 \mathrm{~h}$ ) while BNR and $R$. solani treatments as subplots. Results of histological study were qualitative observations with each assessment done based on the results of two experiments and on the total number observed per treatment. Each treatment was replicated three times. For analysis of pectin and total elements, the experiment was laid out in completely randomized design, repeated twice with five replicates. Data were 
statistically analyzed using Microstat Analysis Progma 2.0 Release (Ecosoft Inc., Indianapolis, IN). Analysis of variance (ANOVA) was performed for the assessed data (each experiment considered as one replicate) in all parameters (disease severity, methanol, uronic acid, calcium content) to test the significance of each treatment. Treatment means were compared using Fisher's least significant difference (LSD, $P=0.05$ and $P=0.01$ ) and Duncan's multiple range test $(P=0.05)$.

\section{RESULTS}

\section{Light and scanning electron microscopy}

Morphological characteristics of the virulent $R$. solani isolate C4 showed slightly-melanized hyphae and irregularly-shaped and brownish sclerotia. Microscopic observation showed short-branched young hyphae produced by the virulent isolate while the non-pathogenic BNR produced long-branched young hyphae. The hyphal width for $R$. solani ranged from 5.0 to $8.0 \mu \mathrm{m}$ while for the nonpathogenic BNR, ranged from 3.0 to $6.0 \mu \mathrm{m}$.

After inoculation on the hypocotyls surface, the hyphae of the virulent isolate of $R$. solani grew longitudinally, but did not grow along the anticlinal walls of the adjacent epidermal cells. It colonized and penetrated the outer surface of the hypocotyls, while the penetrating hyphae ramified through surface. Enzymatic substance was released by the fungus, which macerated the outer epidermal cells and disintegrated the host tissues (Figure $1 \mathrm{~A})$. The base portion of the hypocotyls until the older portion of the root was fully colonized and fully grown and young hyphae of $R$. solani were produced $24 \mathrm{~h}$ after inoculation (Figure 1B). Direct penetration was observed through hyphal tips which grew over the surface or between ridges of adjacent epidermal cells. The hyphae of $R$. solani penetrated the epidermal and cortical cells (Figure 2A). Penetration could be observed in the pith of the hypocotyls. Three days after inoculation, the virulent isolated occupied the parenchymatic cells and extensively macerated the tissues.

The non-pathogenic BNR densely colonized the outer surface of the lower hypocotyls, the whole taproot and a part of the lateral root adjacent to the taproot. The hyphae did not penetrate the cortical cells but colonized the outer surface of the epidermal cells $12 \mathrm{~h}$ after inoculation (Figure 1C). Upon inoculation of the BNR, accumulation of the mucilageinous material occurred on the surface of the hypocotyl until it became profused and lysed the hyphae of BNR (Figure 1D). Accumulation of mucilaginous material occurred not only on surfaces directly in contact with the hyphae but also on surface where no hyphae were found (Figure 1C). Stained section of the basal hypocotyls showed profused accumulation of mucilaginous material which lysed the hyphae of the non-pathogenic BNR on the epidermal and subepidermal layers as shown by the dark bluish- colored portion stained by phenyl-thionin (Figure 2B). The greater stain concentration was especially apparent outside the cell walls and the substance with affinity of phenyl-thionin appeared from the epidermal region. The cortical cells were still intact and no hypha of BNR was observed.

The formation of mucilaginous material which occurred on the hypocotyls surface upon inoculation of the nonpathogenic BNR restricted the growth of the virulent isolate. Pre-inoculation with the non-pathogenic BNR followed by challenge-inoculation with the virulent isolate showed constrict deformed hyphae of the virulent isolate which were prevented to penetrate the epidermal cells (Figure 1E). Hyphae of the virulent isolate of $R$. solani, which could not penetrate the host epidermal cells, were observed mainly above the lysed mycelia mat of the BNR. Later, the mycelia mat was lysed together with the hyphae of the non-pathogenic BNR and formed a gel layer (Figure1F). Hyocotyl sections pre-inoculated with non-pathogenic BNR followed by challenge-inoculated with virulent $R$. solani C4 after $24 \mathrm{~h}$ showed intact epidermal and cortical cells. Although the outer epidermal cells were sloughed-off (Figure 2D), radiating from this area for a distance of an additional three cells increased wall staining by phenyl-thionin which appeared blue. The affinity of cellulose in host cells to Orange $G$ stain caused similar appearance of the stained sections of the hypocotyls of non-treated seedlings, seedlings inoculated with mycelia disks of killed pathogen and PDA only (Figure 2C).

Since phenyl-thioninn has an affinity to pectic materials such accretion of the stain on the cell walls indicate pectic substance accumulation. To verify this suggestion, ruthenium red was also used for free-hand cross-sections hypocotyls of seedlings which had the same treatment. A clear differentiation of red stained cell walls and outer epidermal cells was observed for seedlings treated with non-pathogenic BNR in contrast to deep pink stained cross section of healthy and unstained cross-section of seedlings inoculated with virulent $R$. solani (Table 1 ). The results reveal by ruthenium red staining indicated that the pectic substance present on cell walls and on hypocotyls surface is pectin.

\section{Reduction in severity of Rhizoctonia damping-off disease}

The cucumber seedlings grown on water agar and treated with mycelia disks of hypovirulent/ nonpathogenic BNR isolate W7 two days prior to inoculation of the virulent $R$. solani isolate $\mathrm{C} 4$ showed a low disease severity $(D S I=1.4)$ which is highly significant compared with hypocotyls of seedling inoculated with virulent $R$. solani without non-pathogenic BNR (Figure 4).

The BNR isolate provided $63.2 \%$ protection to the seedling against the pathogen. The cucumber seedling inoculated with the non-pathogenic BNR alone exhibited low disease severity $(0.2)$ which indicate faint lesion and slight browning of the root portion and can be considered as a non-pathogenic reaction. 


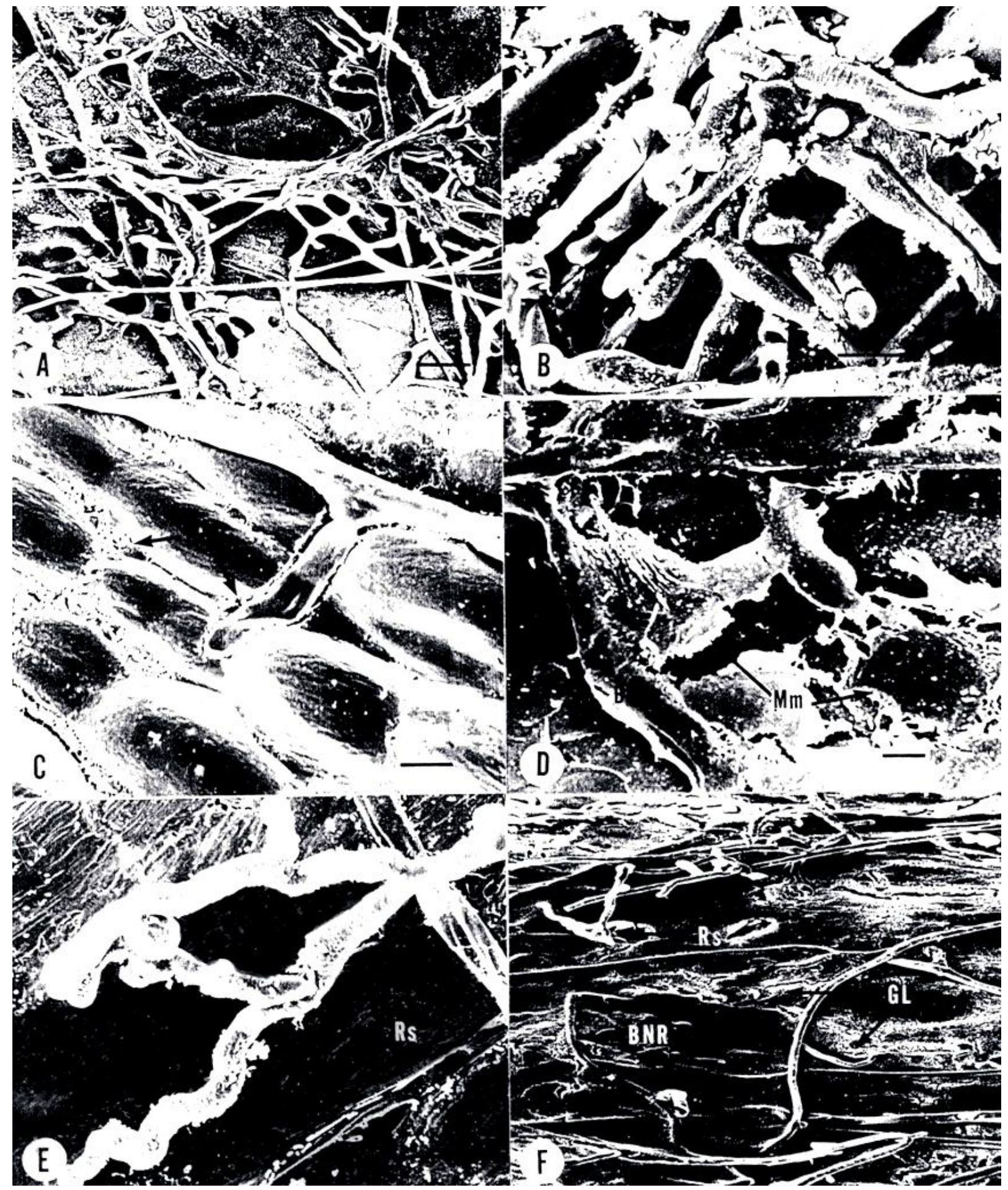

Figure 1. Scanning electron micrographs (SEM) of: A) cucumber hypocotyls surface inoculated with $R$. solani C4 only showing hyphae ramifying through the lesion with macerated epidermal cells and disintegrated host tissues $24 \mathrm{~h}$ after inoculation. Bar=50 $\mu \mathrm{m}$; B) hypocotyl surface inoculated with $R$. solani C4 only showing fully grown, young hyphae of $R$. solani $24 \mathrm{~h}$ after inoculation. Bar $=10$ $\mu \mathrm{m}$; C) colonization of the hypocotyls surface inoculated with BNR W7 only $12 \mathrm{~h}$ after inoculation and initial accumulation of mucilaginous material on the surface directly in contact with the hyphae and also in areas where hyphae was not found Bar $=10 \mu \mathrm{m}$; D) profused production of mucilaginous material which lysed the hyphae of BNR W7 on hypocotyls surface inoculated with BNR W7 only Bar $=10 \mu \mathrm{m} ; \mathrm{E})$ constricted and deformed hyphae of $R$. solani C4 on hypocotyls surface previously inoculated with BNR W7 and challenge inoculated with $R$. solani C4. Bar=10 $\mu \mathrm{m}$; F) hypocotyl surface showing accumulation of mucilaginous material which occurred $12 \mathrm{~h}$ after inoculation with BNR W7, which subsequently lysed the BNR hyphae and turned into a gel layer while $R$. solani C4 which was challenge inoculated could not penetrate the epidermal cells and was observed mainly above the lysed mycelia mat of BNRW7. Bar $=50 \mu \mathrm{m}$. Mm, Mucilaginous material; GL, gel layer; BNR, binucleate Rhizoctonia; Rs, $R$. solani. 


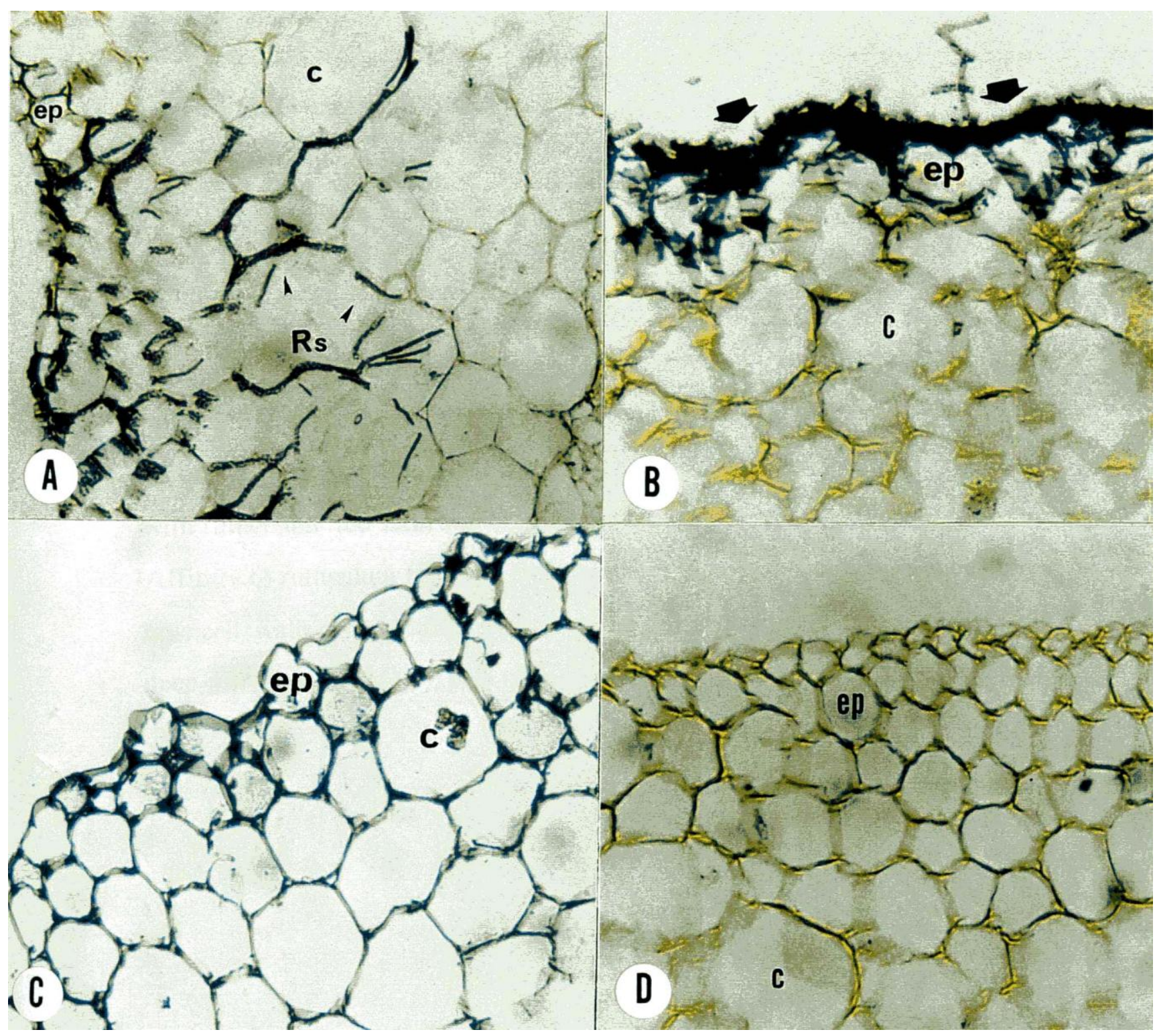

Figure 2. Light micrographs of cross-sections of cucumber hypocotyls stained with phenyl-thionin and counterstained with Orange G showing A, Hyphal penetration of $R$ solani (Rs) into the epidermal and cortical cells of seedling hypocotyls inoculated with $R$. solani C4 only; B, cross-section inoculated with BNR W7 only showing accumulation of mucilaginous material (arrows) in the epidermal and sub-epidermal layers as shown by the dark-bluish colored portion stained by phenyl-thionin and non=penetration of BNR W7 into cortical cells; C, cross-section of uninoculated seedlings showing affinity to Orange G indicating undisturbed cells; D, cross-section previously inoculated with BNR and challenge inoculated with $R$. solani showing intact epidermal and cortical cells which are deeply-stained by phenyl-thionin indicating pectic substance accumulation on the cell walls. All micrographs were taken 40x. ep, Epidermal cells; C, cortical cells, Rs, R. solani; BNR, binucleate Rhizoctonia.

Earlier experiment had shown that un-inoculated seedlings did not show any symptoms of the disease and all treatments showed similar results. Thus, only the data for treatment of un-inoculated seedlings were considered for disease severity rating and tissue analysis.

\section{Nature of pectic substance on hypocotyls tissues}

Analysis of total pectin content of the dried hypocotyls tissues of cucumber seedlings indicated by percentage of methanol and amount of uronic acid. Results showed that percentage of methanol in hypocotyls tissues inoculated with virulent $R$. solani without non-pathogenic BNR were highly significant compared with other treatments (Table 2).

However, the methanol content of hypocotyls tissues inoculated with virulent $R$. solani and non-pathogenic BNR and hypocotyls tissues treated with non-pathogenic BNR alone showed similar results and were both significantly different than the control. 
Table 1. Location of pectic substances using ruthenium red stain in hypocotyls tissues of cucumber seedlings inoculated with virulent $R$. solani with and without non-pathogenic BNR ${ }^{1}$

\begin{tabular}{|c|c|}
\hline Treatment & Affinity to stain ${ }^{2}$ \\
\hline R. solani without BNR & - \\
\hline R. solani with BNR & ++ \\
\hline Nonpathogenic BNR & +++ \\
\hline Uninoculated & + \\
\hline \multicolumn{2}{|c|}{$\begin{array}{l}{ }^{1} \text { Seedlings grown in } 2 \% \text { water agar were inoculated on the base of the } \\
\text { hypocotyls with either non-pathogenic BNR or } R \text {. solani. Free-hand } \\
\text { cross-sections ( } 50 \text { cross-sections) from each treatment were obtained } \\
\text { on the site of inoculation and treated with ruthenium red stain and } \\
\text { examined microscopically. }{ }^{2} \text { Affinity to ruthenium red stain indicate the } \\
\text { presence of pectic substances in the host cell walls. Stain } \\
\text { differentiation of the cell walls in each cross-section showed deep-red } \\
(+++) \text {, red }(++) \text {, pale pink }(+) \text {, and unstained. }\end{array}$} \\
\hline
\end{tabular}

Table 2. Pectin content in dried hypocotyls tissues of cucumber seedlings inoculated with virulent $R$. solani with and without the non-pathogenic binucleate Rhizoctonia.

\begin{tabular}{lcc}
\hline Treatment & Methanol (\%) & Uronic acid (meq/g) \\
\hline R. solani without BNR & $60.0^{\mathrm{a}}$ & $7.0^{\mathrm{c}}$ \\
R. solani with BNR & $50.1^{\mathrm{b}}$ & $7.7^{\mathrm{b}}$ \\
Nonpathogenic BNR alone & $50.2^{\mathrm{b}}$ & $8.3^{\mathrm{a}}$ \\
Uninoculated & $29.3^{\mathrm{c}}$ & $7.4^{\mathrm{bc}}$ \\
\hline
\end{tabular}

${ }^{1}$ Means values of two experiments. Values in columns followed by the same letter (s) are not significantly different $(P=0.05)$ using Duncan's multiple range test.

Table 3. Analysis of total elements in the extracts of cucumber hypocotyls colonized by virulent $R$. solani with and without non-pathogenic binucleate Rhizoctonia using inductively coupled plasma atomic absorption spectrophotometer ${ }^{1}$.

\begin{tabular}{lccccccccc}
\hline Treatment & $\mathbf{N a}$ & $\mathbf{M g}$ & $\mathbf{P}$ & $\mathbf{K}$ & $\mathbf{C a}$ & $\mathbf{M n}$ & $\mathbf{F e}$ & $\mathbf{C u}$ & $\mathbf{Z n}$ \\
\hline R. solani without BNR & 18.4 & 12.9 & 41.9 & 13.4 & $8.8 \mathrm{~b}^{2}$ & 0 & 0.4 & 0 & 0 \\
R. solani with BNR & 17.2 & 15.6 & 38.6 & 14.2 & $10.5 \mathrm{a}$ & 0 & 0.5 & 0 & 0.3 \\
Nonpathogenic BNR alone & 24.2 & 20.5 & 45.2 & 15.7 & $15.4 \mathrm{a}$ & 0 & 0.9 & 0 & 0.2 \\
Uninoculated & 17.3 & 17.3 & 38.0 & 9.5 & $8.0 \mathrm{~b}$ & 0 & 0.7 & 0 & 0.4 \\
\hline
\end{tabular}

${ }^{1}$ Mean values of two experiments; ${ }^{2}$ Values followed by the same letter are not significantly different $(P=0.05)$ using Duncan's multiple range test.

The total uronic acid content of hypocotyls tissues inoculated with virulent $R$. solani without non-pathogenic BNR was significantly lower than the hypocotyls tissues inoculated with virulent $R$. solani and protected by nonpathogenic BNR. It was also significantly different when compared with hypocotyls inoculated with non-pathogenic BNR alone (Table 2). However, in comparison with control, hypocotyls tissues inoculated with virulent $R$. solani with and without non-pathogenic BNR showed similar results.

\section{Total elements in extracts of hypocotyls tissues}

Analysis for total elements revealed high amounts of $\mathrm{Na}$,
$\mathrm{Mg}, \mathrm{P}, \mathrm{K}, \mathrm{Ca}$ and trace amount of $\mathrm{Fe}$ and $\mathrm{Zn}$ in hypocotyls tissues of BNR- treated seedlings when compared with hypocotyl tissues of seedlings inoculated with virulent $R$. solani and the control (Table 3). However, Zn was not obtained in $R$. solani-treated seedlings as well as $\mathrm{Mn}$ and $\mathrm{Cu}$ which were also absent in other treatments. Concentration of $\mathrm{Ca}$ increased in $R$. solani-treated seedlings and BNR treated seedlings compared with other treatments.

The amount of calcium obtained from the hypocotyls tissues inoculated with non- pathogenic BNR alone is double in proportion to the amount of uronic acid obtained in hypocotyls tissues having the same treatment. Additionally, $\mathrm{Na}$ content was increased in BNR 

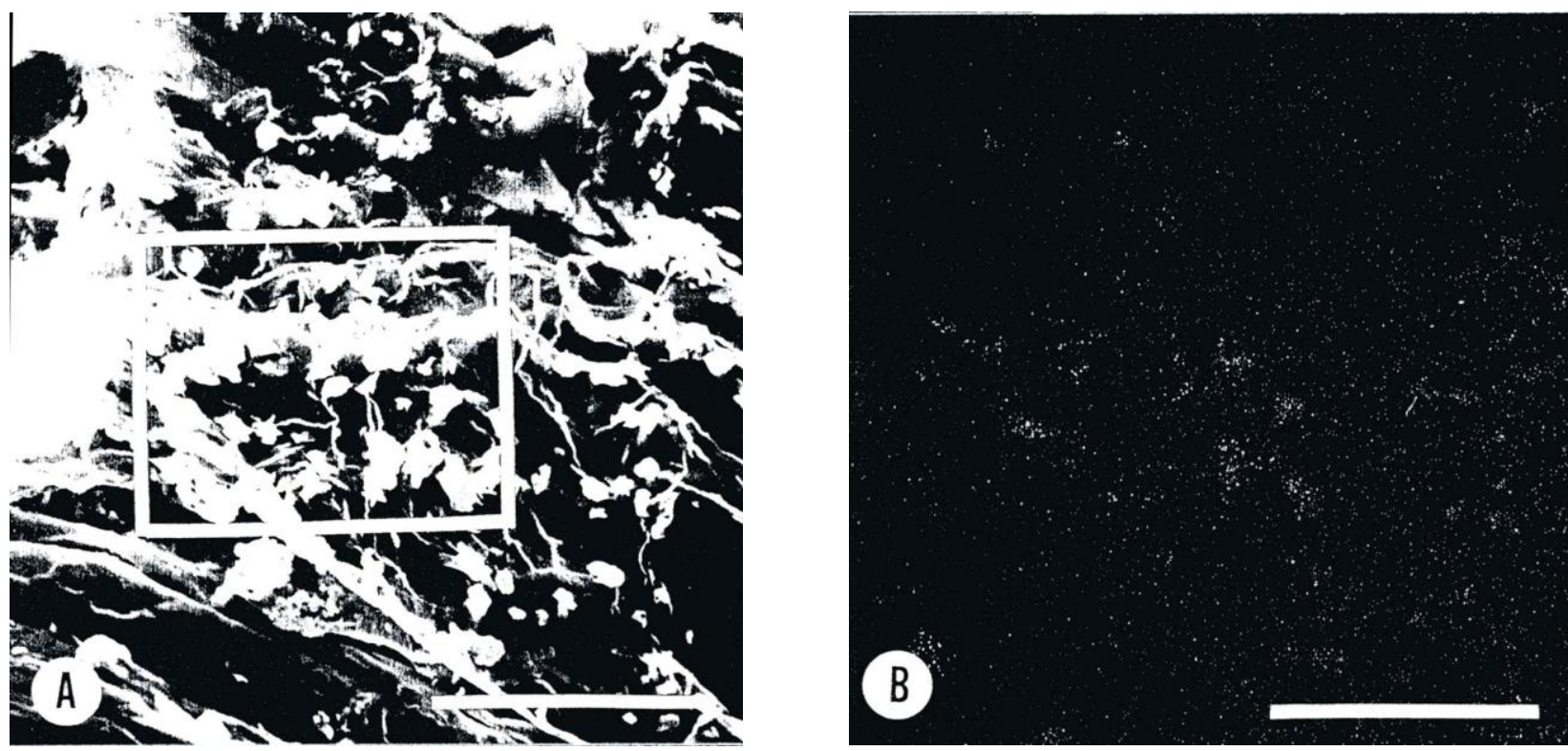

Figure 3. Scanning electron micrographs (SEM) of cucumber hypocotyls surface showing: A) distribution of crystal-like deposits on hypocotyls surface inoculated with BNR W7 only which appeared as calcium salts. The outline shows the area scanned with $\mathrm{x}$-ray detector. Bar $=15 \mu \mathrm{m}$; B) $\mathrm{x}$-ray dot map in which calcium intensity is shown by white spots. Bar $=15 \mu \mathrm{m}$.

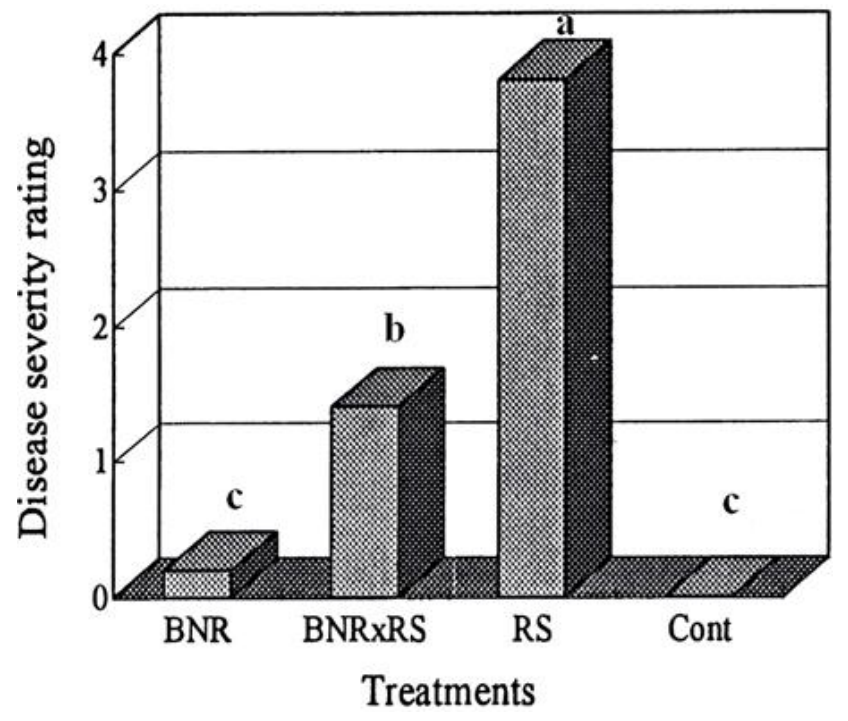

Figure 4. Reduction in severity of Rhizoctonia damping-off disease on cucumber seedlings grown in water agar caused by virulent $R$. solani C4 (AG4) as protected by nonpathogenic binucleate Rhizoctonia W7. LSD values for comparison of treatment means are $0.57(P=0.05)$ and 1.70 $(P=0.1)$.

alone-treated seedlings compared with other treatments.

\section{Analysis with a wavelength-dispersive X-ray microanalyzer}

Hypocotyls of seedlings inoculated with BNR isolates showed crystal-like deposits such as calcium salts (Figure 3A). These deposits were not observed on hypocotyls inoculated with $R$. solani without the BNR and uninoculated seedlings. The area scanned with X-ray detector showed X-ray dot map shown as white spots which indicate high calcium intensity in areas where crystal-like deposits are present (Figure 3B).

\section{DISCUSSION}

The infection process by which the virulent $R$. solani Kuhn (Thanatephorus cucumeris, Donk.) penetrates the host surface was described in various ways (Floyd and Ohlorogge, 1970; Marshall and Rush, 1980; Staples and Macko, 1980; Armentrout and Downer, 1987; VillajuanAbgona et al., 1993). In the present study, the hyphae of the virulent $R$. solani C4 (AG4) colonized the outer surface of the cucumber hypocotyls and directly penetrated the host tissues through hyphal tips which grew through the groves in between ridges of the outer epidermal cells.

Contrary to the findings observed on cucumber hypocotyls inoculated with virulent isolate, direct penetration by non-pathogenic BNR W7 was not observed and instead profused production of mucilaginous material was observed on the cuticular layer. The mere presence of the hyphae on the surface caused the preliminary synthetic of mucilage on the cuticular layer which lysed the BNR hyphae and later turned into a gel layer. This process was clearly revealed by the paraffin sections and hypocotyls surfaces examined through light and scanning electron microscopy, but this gel layer was entirely diffe- 
rent from the reported mucilage (produced by the virulent $R$. solani) which is needed preliminarily for infection cushion formation (Armentrout et al., 1987; Sneh et al., 1989). In addition, the appearance of the reported mucilage was less dense than the gel layer which was produced on the hypocotyl surface upon inoculation with the non-pathogenic BNR. Since mucilaginous material was not observed on hypocotyls inoculated with virulent $R$. solani only, its presence on the hypocotyls surface was largely due to BNR colonization and not due to $R$. solani. The mucilage which was formed and lysed the hyphae of both the non-pathogenic BNR and $R$. solani prevented the virulent $R$. solani from penetrating the outer epidermis and completely covered the hypocotyls surface. The matrix of the mucilage which developed into a gel layer appeared homogenous and lacking any kind of structure.

Previous report discussed in plant nutrition through their effect on citation exchange and diffusion (Balandreau and Knowles, 1978). It occurred in several crops namely azalea (Leiser, 1968), onion (Scott et al., 1958), barley (Jenny and Grossenbacher, 1963), corn (Floyd and Ohlorogge, 1970; Wright and Northcote, 1974) and wheat (Northcote and Pickett-heaps, 1966) and were referred to as plant mucigels. However, the mucilage was not reported on cucumber and the mucilaginous material that was synthesized on the hypocotyls and root surface of cucumber seedlings upon inoculation of the non-pathogenic BNR was unknown.

The mucilage which turned into gel layer on the hypocotyls surface inoculated with non-pathogenic BNR was deeply stained by phenyl-thionin and strongly absorbed ruthenium red describing its nature as pectin (Leiser, 1968; Sterling, 1970). Pectic polysaccharides consist of galacturonan blocks which are heavilybranched with either large-methyl-esterified blocks and un-branched block which could aggregate through calcium binding to the junction zones which hold a gel together (Jarvis, 1984). Micro-scopic observation of the cucumber hypocotyls surface and its stained crosssections showed that the gel-like substance exhibited affinity to phenyl-thionin and ruthenium red stains were indeed pectin. However, since pectic substances consist of acid and calcium gels in the junction zones (Rees and Wight, 1971), these sub-stances might have been detrimental to the hyphal growth of both the nonpathogenic BNR and the virulent $R$. solani. Pectic substances could cause lysis of the hyphae which later were incorporated into the gel layer. Lysis of the BNR hyphae could be primary due to the behaviour of the acidic galacturonic acid block which is an essential component of pectin. Pectin structure in host tissues of other crops was measured as pKa (logarithmic acidic constant) $=3.52$ under acidic condition $(\mathrm{pH} \mathrm{3.6)}$ (Jarvis, 1984). This acidic condition could not be tolerated by the non-pathogenic BNR hyphae and virulent $R$. solani which effectively grew and produced extracellular enzymes to catalyze cutin on cutinase selective medium only in conditions with $\mathrm{pH}$ ranges of 5.2 and 7.2 , respectively (data not shown).

Results of the analysis of pectin through extracted anhydrouronic acid using the Versense-pectinase method (McCready and McComb, 1952) and liberated methanol by distillation method (Boos, 1948) from dried hypocotyls tissues further proved that the mucilage which was synthesized by the hypocotyls tissue was due to BNR treatment. Evidence has shown that pectic fragments released by fungal or host enzymes can elicit the cascade of defense reactions in plant cells which in favourable cases contain the growth of the pathogen (Hahn et al., 1981; Jin and West, 1984). In this experiment, it was evidently shown by significant differences in the proportion of pectin content obtained from hypocotyls inoculated with BNR when compared to the non-treated hypocotyls and hypocotyls treated with virulent $R$. solani. Galacturonic acid blocks consisting of methyl esters which are normally distributed are released as methoxyl groups after acid hydrolysis and expressed as percentage methanol (Boos, 1948). In this experiment, the methoxyl groups in the extracted pectin in the BNRtreated and non-treated hypocotyls were less methylated when compared to the highly methylated pectin of the $R$. solani -treated hypocotyls (Table 2). This indicates that methyl esters in pectic substances of the $R$. solanitreated hypocotyls were less-bound and were completely affected by the pectin esterase and polygalacturonase released by the pathogen. In addition, results of the analysis of calcium and potassium of $R$. solani- treated hypocotyls also indicate the direct loosening effect of the pectic fraction (Sentenac and Grignon, 1981; Jarvis, 1984). However, for BNR-treated seedling, high calcium content which is double in portion to the uronic acid content (Tables 2 and 3 ) resulted in more calcium cations which are wall-bound and pectin is considered a large aggregate unit (Jarvis, 1984). While in non-treated seedlings, calcium was of considerable amount in proportion to uronic acid content and can be considered wall-bound because it is a single primary unit. The same proportion of calcium and uronic was observed in $R$. solani-treated seedlings (Tables 2 and 3 ), but the cations were not wallbound and eventually lose pectin due to pectic enzymes (Leiser, 1968). Similar study conducted by Bateman and Lumsden (1965) in older bean hypocotyls (resistance to damping-off) showed that more total calcium saturated its pectin in their cell walls and this implied that the legume stems contained pectin of large aggregates, if most of the calcium is in the cell wall (Jarvis, 1984). In another experiment (Tepfer and Taylor, 1981), $\mathrm{Ca}^{2+}$ showed a strong ability to form gels with purified, de-estrified pectin, when compared with $\mathrm{Mg}^{2+}, \mathrm{Mn}^{2+}, \mathrm{Co}^{2+}$ and $\mathrm{Zn}^{2+}$. The same experiment also disproved the hypothesis that cation-induced inhibition of the growth response is caused by pectic gel formation in the cell wall but it rather played an important role in rendering the cell wall struc- 
ture inaccessible for microorganisms.

Studies conducted regarding the presence of calcium cations in resistant host tissues showed its importance in disease control (Bateman and Lumsden, 1965; Stockwell and Hanchey, 1982; Akino et al., 1987; Yang et al., 1993; Biggs et al., 1994). Crystal deposits of calcium salts observed on the hypocotyls surface of BNR-treated seedlings (Figures $3 A$ and $B$ ) proved its essential role in the suppression of damping-off in cucumber. This was supported by the results obtained by Akino et al. (1987) which revealed calcium salts on $R$. solani hyphae causing sugarbeet root rot. The authors correlated the appearance of calcium oxalate to the disease decline. In addition, a study revealed that calcium deprivation in cell walls of cucumber roots caused breakdown of pectic polysaccharide which stimulated polygalacturonase activity, thereby predisposing the cucumber seedlings to fungal attacks (Konno et al., 1984). On the other hand, previous study showed the positive effect of BNR isolate W7 on plant growth promotion in terms of significant increase in plant height $(P=0.01)$ and fresh weight $(P=$ 0.05) (Villajuan-Abgona et al., 1996a).

Histochemical investigation of treated cucumber hypocotyls and biochemical analysis of extracts of host tissues evidently showed the importance of calcium and pectic substance accumulation as a result of BNR inoculation to the suppression of the disease caused by the virulent $R$. solani C4. However, the factor which elicited the physiological response of the cucumber tissues to produce profused mucilaginous pectic materials and increased calcium on hypocotyl surface is still obscure. Previous study discussed the secretion of mucigel on epidermal cell walls on wheat as a golgimediated response (Villajuan-Abogna et al., 1996b). The mucigel identified as pectic substance as shown by radioactive analysis, is a polysaccharide synthesized in the golgi apparatus of the root cap cells from where they move in through the cytoplasm and diffused to the plasmalemma (cell membrane) and ejected to the cell wall (pinocytosis). Another study supports the previous result which indicates the involvement of golgi apparatus in the secretion and targeting of cutinase by germinating spores of Fusarium solani f. sp. pisi on epidermal cell wall as a recognition response (Wyllie, 1962). Since colonization of the hypcotyl surface of the cucumber seedlings by BNR hyphae is necessary to synthesize pectic substances to effect the suppression of the disease, a fungal enzyme inherent in the non-pathogenic BNR might be responsible for this induced physiological response. Thus, a continuing study on the extraction and purification of fungal enzymes such as cutinase which could have elicited such physiological response is being conducted.

\section{REFERENCES}

Akino S, Hyakumachi M, Kobayashi K, Ogoshi A (1987). Crystal-like deposits on the hyphae of Rhizoctonia solani. Trans. Mycol. Soc.
Japan 28:351-357

Armentrout VN, Downer AJ (1987). Infections cushion development by Rhizctonia solani on cotton. Phytopathology 77:619-623.

Armentrout VN, Downer AJ, Grasmick DL, Weinhold AR (1987). Factor affecting infection cushion development by Rhizctonia solani on cotton. Phytopathology 77:623-630.

Balandreau J, Knowles R (1978). The rhizoshere. P 243-268 in: Interaction between non-pathogenic soil Microorganisms and plants. Y. R. Dommergues and S.V. Krupa, eds. Elsevier Scientific Publishing company, Amsterdam, The Netherlands.

Bateman DF, Lumsden RD (1965). Relation of calcium content and nature of pectic substances in bean hypocotyls of different ages to susceptibility to an isolate of Rhizoctonia solani. Phytopathology 55:734-738.

Biggs AR, El-kholi MM, El-Neshewy SM (1994). Effects of calcium salts on growth, pectic enzyme activity and colonization of peach twigs by Leucostoma persoonii. Plant Dis. 78:886-890.

Boos RN (1948). Quantitative colorimetric microdetermination of methanol with chromotropic acid. Anal. Chem. 20:964-965.

Burpee LL, Goulty LG (1984). Suppression of brown patch disease creeping bentgrass by isolates of non-pathogenic Rhizoctonia spp. Phytopathology 74:692-694.

Cardoso JE, Echandi E (1987a). Biological control of Rhizoctonia root rot of snap bean with binucleate Rhizoctonia-like fungi. Plant Dis. 71:167-170.

Cardoso JE, Echandi E (1987b). Nature of protection of bean seedling from Rhizctonia root rot by abinucleate Rhizctonia-like fungus .Phytopathology 77:1548-1551.

Christou T (1962). Penetration and host -parasite relationship of Rhizctonia solani in the bean plant. Phytopathology 52:381-389.

Cubeta MA, Echandi E (1991). Biological control of Rhizctonia and Pythium damping-off of cucumber: An integrated approach. Biol. Control 1:227-236.

Escande AR, Echandi E (1991). Protection of potato from Rhizoctonia canker with binucleate Rhizoctonia fungi. Plant Pathol. 40:197-202.

Floyd RA, Ohlorogge AJ (1970). Gel formation on nodal root surfaces of Zea mays I: Investigation of the gel's composition. Plant Soil 33:331343.

Hahn MG, Darvill AG, Albersheim P (1981). Host-pathogen interactions. $X I X$. The endogenous elicitors, a fragment of a plant cell wall polysaccharide that elicits phytoalexin accumulation in soybeans. Plant Physiol. 68:1161-1169.

Herr LJ (1988). Biocontrol of Rhizoctonia crown and root rot of sugar beet by binucleate Rhizoctonia spp. and Laetisaria arvalis. Ann. Appl. Biol. 113:107-118.

Jabaji-Hare S, Neate SM (2005). Nonpathogenic binucleate Rhizoctonia spp. and benzothiadiazole protect cotton seedlings against Rhizoctonia damping-off and Alternaria leaf spot in cotton. Phytopathology 95:1030-1036.

Jarvis MC (1984). Structure and properties of pectin gels in plant cell walls. Plant Cell Environ. 7:153-164.

Jenny H, Grossenbacher K (1963). Root-soil boundary zone as seen in the electron microscope. Soil Sci. Soc. Amer. Proc. 27:273-277.

Jin DF, West CA (1984). Characterizatics of galacturonnic acid oligomers as elicitors of casbene synthetase activity in castor bean seedlings Plant Physiol. 74:989-992.

Johansen DA (1940). Plant Microtechnique. McGraw-Hill, New York. $523 \mathrm{pp}$.

Konno H, Tomoyuki Y, Matsumoto H (1984). Pectic polysaccharide breakdown of cell walls in cucumber roots grown with calcium starvation. Plant Physiol. 76:633-637.

Leiser AT (1968). A mucilaginous root sheath in Ericeae. Amer. J. Bot. 55(3):391-398.

Marshall DS, Rush MC (1980). Relation between infection by Rhizctonia solani and Rhizctonia oryzae and diseases severity in rice. Phytopathology 70:941-946.

McCready RM, McComb EA (1952). Extraction and determination of total pectic materials in fruits. Anal. Chem. 24 (12):1986-1988.

Northcote DH, Pickett-heaps JD (1966). A function of the golgi apparatus in polysaccharide synthesis and transport in the root cap cells of wheat. Biochem. J. 98(1):159-167.

Pascual CB, Raymundo AD, Hayakumachi M (2000). Efficacy of hypovi- 
rulent binucleate Rhizoctonia sp. to control banded leaf and sheath blight in corn. J. Gen. Plant Pathol. 66:95-102

Rees DA, Wight AW (1971). Polysaccharide conformation VIII. Model building computations for alpha-1, 4- galacturonan and the kinking function of L-rhamnose residues in pectic substances. J. Chem. Soc. Section B. 1366-1372.

Scott FM, Hamner KC, Baker E, Bowler E (1958). Electron microscope studies of the epidermis of Allium Cepa. Amer. J. Bot. 45:449-460.

Sentenac H, Grignon C (1981). A model for predicting ionic equilibrium concentrations in cell walls. Plant Physiol. 68:415-419.

Sneh B, Ichielevich-Auster M, Scomer I (1989). Comparative anatomy of colonization of cotton hypocotyls and roots by virulent and hypovirulent isolates of Rhizoctonia solani. Can. J. Bot. 67:21422149.

Sneh B, Yamoah E, Stewart A (2004). Hypovirulent Rhizctonia spp. isolated from New Zealand soil protect radish seedling against damping-off by $R$. solani. New Zealand Plant Prot. 57:54-58.

Staples R, Macko V (1980). Formation of infection structures as a recognition response in fungi. Exp. Mycol. 4:2-16.

Sterling C (1970). Crystal structure of ruthenium red and stereochemistry of its pectin stain. Am. J. Bot. 57:172-175.

Stockwell V, Hanchey P (1982). Cyohistochemical techniques for calcium localization and the application to diseased plants. Plant Physiol. 70:244-451.

Stoughton RH (1930). Thionin and Orange G for thr differential staining of bacteria and fungi in plant tissues. Ann. Appl. Biol. 17:162-164.
Tepfer M, Taylor IEP (1981). The interaction of adjvalent cations with pectic substances and their influence on acid-induced cell wall loosening. Can. J. Bot. 59:1522-1525.

Villajuan-Abgona R, Kageyama K, Hyakumachi M (1993). Biological control of Rhizctonia damping-off of cucumber by binucleate Rhizctonia: Prevention of hyphal penetration. Ann. Phytopath. Soc. Japan 60(6):780.

Villajuan-Abgona R, Kageyama K, Hyakumachi M (1996a). Biological control of Rhizctonia damping -off of cucumber by non-pathogenic binucleate Rhizctonia. Eur. J. Plant Pathol. 102:227-235.

Villajuan-Abgona R, Katsuno N, Kageyama K, Hyakumachi M (1996b). Isolation and identification of hypovirulent Rhizoctonia spp. form soil. Plant Pathol. 45:896-904.

Wright K, Northcote DH (1974). The relationship of root-cap slimes to pectins. Biochem. 139:525-534.

Wyllie TD (1962). Effect of metabolic by -products of Rhizctonia solani on the roots of Chippewa soybean seedlings. Phytopathology 52:202206.

Yang J, Tewari JP, Verma PR (1993). Calcium oxalate crystal formation in Rhizoctonia solani AG2-1 culture and infected crucifer tissue: relationship between host calcium and resistance. Mycol. Res. 97(12):1516-1522. 